\title{
PROPOSTA DE UM SISTEMA DE INTEGRIDADE AOS ÓRGÃOS GOVERNAMENTAIS NO BRASIL NO TOCANTE A CORRUPÇÃO
}

\section{PROPOSAL FOR A SYSTEM OF INTEGRITY TO GOVERNMENT AGENCIES IN BRAZIL REGARDING CORRUPTION}

\author{
Charleston Sperandio de Souza, \\ Mestre e Professor de Administração pela Alfa Unipac, Aimorés, Brasil . \\ E-mail: charleston.sperandio@yahoo.com.br
}

Recebido: 10/11/2020 - Aceito: 27/11/2020

\section{Resumo}

O presente estudo realizou uma análise sobre os órgãos governamentais e a Corrupção no Brasil. O campo do estudo sobre "corrupção" tem crescido em relevância no âmbito dos estudos da ciência política. O objetivo geral foi de realizar uma análise sobre a relação entre a corrupção e os órgãos governamentais do Brasil, e sugerir um Sistema de Integridade como um instrumento para combater a Corrupção. O marco teórico versou sobre a corrupção, definido como abuso de recursos públicos para fins particulares pela Transparency International. No que concerne aos objetivos, a pesquisa é exploratória e descritiva. Quanto à abordagem, a mesma se classifica como qualitativa, por se ater a compreensão do fenômeno corrupção, entendendo o contexto e a dinâmica dos Órgãos Governamentais, e quanto aos procedimentos, é bibliográfico por desenvolver uma investigação de conhecimentos sistematizados em livros e em bases de dados de artigos e dissertações, analisando a temática de acordo com as contribuições teóricas buscadas. A partir da proposição desse artigo, houve a necessidade de estudar o fundamento lógico a fim de entender o ato da corrupção, e apresentar propostas para um Sistema de Integridade. Por meio das análises dos estudos foram realizadas propostas que foram consideradas relevantes como: o Congresso Nacional delibere reformas estruturantes de anticorrupção agasalhadas nas propostas de medidas formadas por especialistas da área; que o Poder Judiciário e o Ministério Público ajam de frente com mais eficiência administrativa; que o Governo Federal afaste os componentes investigados por corrupção, ainda sugerir ao Congresso Nacional medidas de anticorrupção, devendo abster-se e de se indispor com os profissionais da imprensa; e que a sociedade brasileira exerça conscientemente seus direitos de votar nas eleições vindouras elegendo pretendentes com passado limpo, que se comprometa com a pauta contra a corrupção e tenham respeito com os valores democráticos.

Palavras chaves: Sistema de integridade, órgãos governamentais; corrupção.

\section{Abstract}


The present study conducted an analysis of government agencies and corruption in Brazil. The field of study on "corruption" has grown in relevance in the field of studies of political science. The general objective was to conduct an analysis on the relationship between corruption and government agencies in Brazil, and to suggest an Integrity System as an instrument to combat corruption. The theoretical framework focused on corruption, defined as abuse of public resources for private purposes by Transparency International. With regard to objectives, the research is exploratory and descriptive. As for the approach, it is classified as qualitative, because it has an understanding of the phenomenon of corruption, understanding the context and dynamics of governmental agencies, and regarding procedures, it is bibliographic for developing an investigation of systematized knowledge in books and in databases of articles and dissertations, analyzing the theme according to the theoretical contributions sought. From the proposition of this article, there was a need to study the logical basis in order to understand the act of corruption, and to present proposals for a System of Integrity. Through the analysis of the studies, proposals were made that were considered relevant as: the National Congress deliberates structuring reforms of anti-corruption wrapped in the proposals for measures formed by experts in the area; that the judiciary and the public prosecutor act more efficiencyly administratively; that the Federal Government removes the components investigated for corruption, and also suggests to the National Congress anti-corruption measures, and should refrain and be undisposed with the professionals of the press; and that Brazilian society consciously exercise its rights to vote in the coming elections by electing suitors with a clean past, who commits to the agenda against corruption and has respect for democratic values.

Key Word: Integrity system, government agencies; corruption.

\section{Introdução}

O tema corrupção é sem dúvida, um dos enfoques na política que agora têm um dos maiores destaque público, e a presença nos debates políticos e na mídia jornalística tem sido frequente. Considera-se o tema como um dos mais mencionados em forma descritiva, pois, pressupõe que existe uma considerável razoabilidade de pesquisa empírica, mas há controvérsia sobre a temática.

Pode-se dizer que a corrupção é um conceito teórico e subjetivo tornando-o difícil de conduzir o pensamento estratégico sobre as suas causas e minimizar os seus efeitos.

Klitgaard (1994) ressalta que a expressão do termo corrupção, possui muitos significados. Significa subdividir e implantar um vasto conceito. Em nível geral, corrupção significa o abuso de função (ou cargo) para fins não oficiais. 
O catálogo de atos de corrupção, inclui corrupção, extorsão, tráfico de seres humanos e de influências, lavagem de dinheiro, nepotismo, fraude, peculato e muito mais.

As propostas de desenvolver políticas que tentam controlar, minimizar ou reduzir os efeitos da corrupção no meio político governamental, exige um forte enfoque sobre os detalhes de sua distintiva demonstração, com desenvolvimento de modelos explicativos, modelos interpretativos, e utilizar as estratégias metodológicas de pesquisa que forneçam conhecimento sistemático que será de grande utilidade para a estruturação de um conjunto de projetos que tendem a superar possíveis continuidade desse mal (SUÁREZ; GORROCHATEGUI, 2000).

Dessa forma, no entendimento de Silva (2001) a corrupção nas instituições públicas é definida como uma correlação social, que é estabelecida entre dois agentes (corruptos e corruptores), que tem por objetivo em comum a transferência ilegal de recursos, dentro de uma sociedade ou de um organismo público, para fins estritamente particulares, e já no entendimento de Pereira (2002), a questão da transparência deve ter lugar de importante destaque nos meios sociais, pois se percebe que a corrupção enfraquece a democracia, gera desconfiança no Estado, e a moral pública fica totalmente abalada.

O autor Pereira (2002), assinala ainda que o exercício da corrupção não é privativo dos países em desenvolvimento, pois se encontram também em maior ou menor grau nos países desenvolvidos.

Assim, qualquer política pública governamental que luta contra a corrupção irá necessitar para desenvolver as estratégias metodológicas, de muita pesquisa contínua, uma vez que controlar as políticas de corrupção pode ser sujeita a desclassificação pela maioria afetada e por diferentes instrumentos de política, programas e projetos propostos.

E para entender o tema corrupção é necessário considerar as estruturas das oportunidades que facilitam ou dificultam o acesso a corrupção e entender também o caso da corrupção institucionalizada, bem como propor que a compreensão dos valores éticos e morais, as normas, condutas, crenças e atitudes que acompanham os processos de corrupção (que surgem de interações geradas pela estrutura das oportunidades em termos de indivíduos e de estratégia da sobrevivência corporativa) que nos permite refletir sobre a profundidade do assunto e a maneira pela 
qual as formas são corrompidas e incorporadas na sociedade atual (SUÁREZ; CHRISTENSEN, 2000).

Além da relevância em poder contribuir para o entendimento desta temática delineada, a justificativa para abordar o tema em questão é a preocupação do autor desse artigo, pois as limitações surgidas como proposta de entender o desenvolvimento das políticas que tentam controlar, minimizar ou reduzir os efeitos da corrupção no meio político governamental, exige um forte enfoque sobre os detalhes de sua distinta demonstração, com desenvolvimento de modelos explicativos e interpretativos, que se renova a cada dia com um fato novo sobre corrupção

Assim, o presente artigo tem como objetivo de realizar uma análise sobre a relação entre a corrupção e os organismos governamentais do Brasil, e sugerir um Sistema de Integridade como um instrumento para combater a Corrupção.

\subsection{A gênese da corrupção na concepção de Aristóteles}

A transformação da sociedade pelos políticos e a corrupção que se sustenta no tema desse artigo, ou seja, de uma proposta do Sistema de Integridade como instrumento das mudanças do comportamento do homem acompanhando a evolução social do mesmo e, pode contextualizar que a abordagem produza espaço dos excluídos da visão clássica da sociedade causada pelos políticos e pela corrupção, os diversos atores envolvidos com a organização política estrutural da sociedade, os seus componentes dos níveis governamentais à alta administração pública, sem se limitar um discurso mais profundo sobre esse último grupo.

Nesse sentido, este artigo procura corroborar com as influências em torno das construções sociais dos atores envolvidos e suas implicações nos órgãos públicos, principalmente sobre a aplicação de uma proposta do Sistema de Integridade como instrumento de luta contra a corrupção.

Há tempo que o problema corrupção é presente na sociedade e vem sendo debatida. De origem improvável, essa contravenção dos inícios pré-estabelecidos pelo dualismo Estado e Sociedade tem surgido como objeto de debate desde a Antiguidade até os dias contemporâneos.

Como bem coloca Aristóteles, a corrupção é como uma transformação na ordem natural das coisas é igual a uma espécie de desvio de conduta. Aristóteles, aplica o termo política, a um assunto único, ou seja - a ciência da felicidade humana 
- dividido em duas partes: a primeira é a ética e a segunda é a política propriamente dita (KURY, 1985).

A felicidade humana consistiria em certa maneira de viver, e a vida de um homem é o resultado de um meio que ele existe, das leis, dos costumes e das organizações adotadas pela sociedade à qual ele pertence.

Não se pode esquecer de que Aristóteles, fora um intenso defensor da propriedade dos bens e um grande desafeto de Platão (KURY, 1985):

a) enquanto que Platão se inclinava às construções da sociedade fantasiosas e virtuais; Aristóteles buscava debater as coisas reais, dos sistemas políticos viventes na sua época, buscando por classificá-los, por defini-los por meio de suas particularidades mais acentuadas, por separá-los em puros ou corrompidos;

b) enquanto que Platão produzia revolucionários e doutrinários da sociedade satisfeita; Aristóteles era o catedrático dos grandes juristas e dos pensadores políticos igualmente inclinados à ciência e ao realismo (KURY, 1985).

O debate sobre a corrupção, que é normalmente determinada como o uso de bens públicos para fins particulares, normalmente rege a certas conjecturas comumente reproduzidas. Nesse sentido, fica fácil ver a corrupção como um assunto de "cultura", dos fatos serem feitos de modo "desigual" em várias partes do mundo, e admitir que a conduta corrupta é comum nas sociedades em desenvolvimento.

No entanto, se isso for verdade, pode-se inquirir por que potencialmente todas as formas de corrupção são coibidas em quase todos os países ou por que a corrupção parece estar crescendo nas sociedades industriais avançadas (KLITGAARD, 1988).

É importante esclarecer que a ética deve abranger o anseio popular com respeito ao destino advindo da sociedade, às pretensões da sociedade quanto a este destino. $O$ conceito de ética obrigatoriamente envolve o empenho de cada um e de todos pelo destino da sociedade, e este empenho, os anseios e pretensões, fundamentalmente se define sob a configuração de concordância, sob pena de tornarse inviável a manutenção da lealdade e, por consecutivo para o bem social. 
O separatismo que se difunde nos dias atuais pelo mundo medita esta reivindicação; não um abrandamento dos laços, fidelidades e anseios sociais, mas, ao avesso, a obrigação de redefinições das unidades, tendo em vista o fato dos vínculos consensuais de ambições quanto ao destino comum.

Já à política, a sua ideia se estende em dois conceitos desiguais que convivem no conceito dos cidadãos e na motivação da ação dos políticos:

a) um é o de que a política, a mais sublime das ocupações humanas, é o empenho na realização do bem comum, do bem da sociedade ao qual se sobrepõe como a um desígnio final; é a concepção de Platão e de Aristóteles, dos filósofos gregos que a mencionaram na sua afirmação da filosofia (que se confundia para eles com a política), versus o pragmatismo dos sofistas e dos retóricos que instruíam a linguagem eficaz para o manejo das assembleias e aos desempenhos políticos.

b) O outro é o de que a política é a arte e a esperteza, da astúcia de conquistar e de conservar estável o poder; o fazer o bem; nesta visão, não é propriamente um fim, mas um meio de ganhar o apoio dos cidadãos para a permanência e a firmação no poder empregado em paralelo com outros meios também válidos, como o marketing, o controle da mídia, o clientelismo, o populismo e até a própria mentira, a violência e a corrupção (KURY, 1985).

Esta é a importância das derivações e das explanações mais correntes dos conselhos de Maquiavel e é o que melhor se enquadra nas percepções da ciência política moderna, entendida a ciência como conhecimento neutro, isto é, desconexo de qualquer importância de natureza ética.

Nessa linha, pode-se citar como exemplo, Ntalaja-Nzongola (2003), que realizou em uma conferência temática no Festival Internacional de estudantes, em Trondheim, Noruega, e fez seu discurso sobre a "corrupção institucionalizada" que continua a ser um grande obstáculo para a consolidação da democracia, ética e política no mundo de hoje. Ao invés de se limitar a corrupção em nova democracia, expandiu o foco geográfico de suas observações a todos os países em transição do autoritarismo para a democracia. Geralmente, estes países são também os países em desenvolvimento.

Em seus relatos, Ntalaja-Nzongola (2003) disse que a corrupção ameaça à democracia, a ética e a política porque ela corrói a capacidade do estado para garantir 
um desenvolvimento sustentável, negando assim as pessoas o gozo de seu pleno direito de cidadania e, consequentemente, exacerbando conflitos violentos. Erradicar a corrupção e melhorar a transparência, responsabilização e integridade em todas as áreas da vida nacional e relações internacionais seriam melhorar o emprego de recursos de desenvolvimento para todos os cidadãos, os pobres, em particular.

A Corrupção é um fenômeno universal; não é limitado aos países em desenvolvimento, é um fato bem conhecido que grupos mafiosos permaneceram poderosos em um número de avançadas democracias, incluindo a Itália e os Estados Unidos.

Neste ponto, deve salientar que um número de países desenvolvidos é beneficiário do dinheiro roubado e ilegalmente transferido para o Norte por governantes corruptos dos países do Sul (NTALAJA-NZONGOLA, 2003).

Nos termos do direito ocidental, segurando ou comprando bens roubados é um crime e isso significa que os bancos do Norte, mercados imobiliários e dinheiro, os mercados de bilhões de dólares no valor de dinheiro roubado do Sul são tão culpados quanto a segurar quem roubou o dinheiro em primeiro lugar. A restituição do dinheiro para os povos do Sul é um imperativo moral e deve ser apoiada por todos os que afirmam respeito pela lei, justiça, a ética e os direitos humanos.

A principal diferença entre países desenvolvidos e em desenvolvimento é que as causas e as oportunidades de corrupção são maiores nos países em desenvolvimento, incluindo:

a) a pobreza e a dificuldade de fazer fim do mês, que incentivar a pequena corrupção entre a baixa de funcionários e agentes da autoridade;

b) a expansão do estado na economia, que oferece a funcionários do governo a oportunidade de procurar as rendas de operadores econômicos;

c) a ausência ou a fraqueza de responsabilidade nacional, a integridade e a transparência, que ajudaram a reduzir a corrupção nos países desenvolvidos.

Uma estratégia global para a luta contrária a corrupção nos países de transição envolve estabelecer e construir a capacidade de responsabilização nacional, a integridade e sistemas de transparência. Tal estratégia exige mudanças atitudinais dentro de todos os estratos da população em favor da tolerância zero para a corrupção e uma forte política será entre líderes políticos nacionais. 
$\mathrm{Na}$ Nigéria, muitos grandes homens são premiados com títulos tradicionais como "chefes" para a construção de escolas, clínicas, etc. com o dinheiro roubado, sem ninguém fazendo a pergunta de onde veio o dinheiro.

$\mathrm{Na}$ África, há necessidade de uma mudança de paradigma em relação às populações e percepções do estado.

Uma cruzada contrária a corrupção requer o surgimento de uma forte luta contra a corrupção, coligação no âmbito de um estado de desenvolvimento envolvendo agências de anticorrupção, sociedade civil e setor privado. Para essa coalizão ter sucesso, ele deve programar dois principais componentes da estratégia de luta contra a corrupção, diz Ntalaja-Nzongola (2003):

1 - Prevenção, que é mais eficaz em longo prazo do que a curta duração satisfação de captura e com sucesso processar o "peixe grande", no entanto pode ser útil como um elemento dissuasor. Medidas de prevenção devem incluir pública conscientização e campanhas educativas sobre a corrupção; simplificação e clarificação as regras e procedimentos do governo; e compensar os funcionários públicos com salários dignos e gratificantes e com bom desempenho.

2 - Sensibilização e apoio, como um meio de facilitar a aprovação do público de medidas de prevenção e de aplicação, maior acesso pela imprensa e comum cidadãos de registros públicos e mais frutíferos, diálogo de política em matéria de transparência, integridade e a responsabilidade por todas as partes interessadas.

Dessa forma, os países desenvolvidos expuseram na terminologia de Johnston (2005) as "síndromes de corrupção" os quais abarcam por um lado, empenhos por artifício de interesses privados, aproveitando o seu ingresso e controle em técnicas políticas maturadas e solidamente institucionalizadas, comumente usando figuras políticas como mediadores; por outro lado, despontam-se em determinadas sociedades, na vivência e desenvolvimento de networks de elites políticas, econômicas, militares, burocráticas, dependendo da sociedade em análise.

Assim, este tipo de corrupção propende defender a supremacia das elites num ambiente de concorrência política crescente e em determinados casos, com instituições ainda não satisfatoriamente maturadas. Concentrando nos países desenvolvidos, estes indícios de corrupção demandam, todavia, em comum, a essência de mercados competentes de acordos corruptos. 


\subsection{O Brasil na concepção da transparência internacional e na perspectiva da corrupção}

Um dos principais modelos de apreciação, delineando as estruturas institucionais de prevenção e controle da corrupção, foi preparado pela Transparency International, baseada em Berlim, sob o nome National Integrity System (NIS). A imaginação de aferir o Sistema Nacional de Integridade foi formulada pela primeira vez em 1996 pela organização Transparency International, destinada a luta contra a corrupção (TRANSPARENCY INTERNATIONAL, 1996).

No Source Book, o Sistema Nacional de Integridade consiste numa união de leis exemplares e melhores técnicas para distintas áreas de controle da corrupção. Uma versão do Source Book para a América Latina foi editada em 1998 com o nome La hora de La Transparencia En America Latina (DIRANI; LOZANO, 1996).

É óbvio, há amplas contestações entre as várias províncias do mundo em afinidade à contemporaneidade desse tema. Em alguns países, o debate sobre a corrupção está absolutamente acomodado na agenda política. Para alguns críticos, o convertimento dos atores políticos ao tema da corrupção é mero oratória, um fogo de palha que acaba ligeiramente. Sem propostas palpáveis, eles se restringiriam às solicitações morais e denúncias pessoais. Seria uma visão diminuída da política, guiada às falhas individualizadas e não estruturais (SANTOS, 1978).

Atualmente, a transparência e a sistematização de integridade são as armas mais competentes para impedir arrumações igualmente consentidas sob a cortina da desinformação. Muitas vezes, a precaução promove também uma revisão de princípios para suplantar circunstâncias de irrealidade legal, que afrontam com um desempenho real radicalmente desigual. Seja pelo fortalecimento dos princípios, seja pela acomodação à realidade, a solução visa suavizar a distância entre os dois mundos, a qual, de outra configuração, é recheada ordenadamente pela corrupção.

As políticas de domínio da corrupção sugeridas nos últimos anos apontam em aperfeiçoar a qualidade das estruturas reguladoras, para impedir que azedem os conflitos entre país legal e país real com acomodamentos corruptos. Ao mesmo tempo, dão uma abordagem específica sobre a referência do Sistema de Integridade e complementação dos diferentes organismos de controle, da simples transparência até a sofisticada investigação, mediante a integração das várias ações na esfera pública, social e privada (SPECK, 2002). 
De acordo com Quintela (2007), a Transparência Internacional ${ }^{1}$ (TI) afirma que a corrupção é o excesso do poder confiado para ganho particular. Este conceito é composto por três elementos: o abuso de poder, o poder confiado (setor público e privado) e lucro privado, o que pode incluir o ator, família, amigos, parceiros, etc.

De acordo com a Transparência Internacional Brasil (2019), o Índice de Percepção da Corrupção (IPC) de 2019 sobre a TI, pode-se garantir que o Brasil obteve uma péssima nota pelo segundo ano consecutivo desde 2018. Em 2019, o Brasil se manteve na pior escala da série histórica do Índice de Percepção da Corrupção, adquirindo apenas 35 pontos.

Os 35 pontos da nota do Brasil equiparam ao índice mais baixo desde 2012, ano em que o identificador teve alteração da metodologia e passou a permitir uma leitura positiva em sua série histórica.

Para ilustrar a situação brasileira no Ranking da TI de 2012, de acordo com o relatório, o Brasil havia ganhado quatro posições positivas no Índice da percepção da corrupção naquele ano de 2012 e ocupava o lugar 69 lugar do ranking. A nota atribuida ao Brasil na escala, estimou um valor que vai de zero para os países de corrupção mais corruptos a 100 para os menos corruptos, e o Brasil obteve 43 pontos (TRANSPARÊNCIA INTERNACIONAL, 2012).

De acordo com as análises de 2019 e com os resultados revelados, o Brasil despencou mais uma posição no ranking de 180 países e territórios, para o 106 lugar.

Este 5o recuo sequenciais na comparação anual, fez com que o Brasil alcançasse ainda a sua pior situação na série histórica dos indicadores. Em 2018, o país já havia perdido dois pontos e caído nove posições (TRANSPARÊNCIA INTERNACIONAL BRASIL, 2019).

Nessa linha, pode-se inferir alguns dados históricos como retrospectiva tendo como partida o ano de 2018.

Naquele ano (2018), o Brasil teve eleições com resultados visivelmente influenciados por essa pauta. O alto índice de renovação de candidatos na política aconteceu com a eleição de candidatos que tinham agasalhados suas

\footnotetext{
${ }^{1}$ Nota do autor: A Transparência Internacional (TI) é uma organização não governamental que tem como principal objetivo o combate contra a corrupção. Fundada em março de 1993 e atualmente a sede encontra-se em Berlim. É conhecida internacionalmente, pois emite anualmente um relatório no qual se analisam os índices de percepçaõ de corrupção dos países do mundo.
} 
propostas eleitorais em intensos discursos de anticorrupção. O Brasil, no entanto, se transpôs o ano de 2019 sem alcançar melhorias e ou reformas que acometessem de fato as origens do problema (TRANSPARÊNCIA INTERNACIONAL BRASIL, 2019).

Poucos progressos e atrasos em séries ocorreram no arcabouço judicial e institucional na esfera da anticorrupção do país. No ano de 2019, por exemplo, uma autorização do Presidente do Supremo Tribunal Federal (STF) praticamente estacionou durante quase a metade do ano de 2019, o sistema de luta à lavagem de dinheiro no Brasil (TRANSPARÊNCIA INTERNACIONAL BRASIL, 2019).

Percebeu-se ainda um acréscimo dos ensaios de mando político do Palácio do Planalto nos órgãos de controle, com mudanças controvérsias na Polícia Federal e Receita Federal e a nomeação de um Procurador-Geral da República ausente da lista tríplice.

Já no Congresso Nacional, constituíram leis na direção contrária ao combate à corrupção, como se cita, por exemplo, a lei que criou estruturas que atenuaram ainda mais a lucidez de partidos e o controle do gasto público em época de campanhas eleitorais (TRANSPARÊNCIA INTERNACIONAL BRASIL, 2019).

O cenário só não piorou mais, porque foi por meio da forte reação da sociedade brasileira e das instituições que alcançaram em barrar alguns atrasos expressivos e abonar alguns progressos. No entanto, o país cruzou 2019 sem alcançar e aprovar melhorias que incidissem de fato às causas do problema (TRANSPARÊNCIA INTERNACIONAL BRASIL, 2019).

\subsection{O pacto de integridade - Uma ferramenta para buscar a limpeza e a contratação dos interesses públicos no brasil}

O Brasil, a partir do ano de 2003, consolidava seu empenho na jornada ao criar o Comitê Brasileiro do Pacto Global ou Pacto de Integridade, sendo mais um integrante desta rede que tutela os direitos humanos, proteção do trabalho humano, meio ambiente e corrupção.

O diagnóstico que se propõe neste capítulo é avaliar os aspectos da ordem jurídica brasileira quanto à conformidade com o Pacto Global ou Pacto de Integridade, especificamente, quanto o combate à corrupção em face dos interesses públicos. 
Sem dúvida, o Estado continua sendo o centro de atribuições, aglomerado em prol da satisfação do interesse público e do bem estar da sociedade, entretanto, não agirá sozinho. A chamada responsabilidade social configura a triangular regulação social de vinculação entre Estado, Empresas e Sociedade. Atentas a esta reivindicação contemporânea surgiram inúmeras entidades não governamentais, nacionais e internacionais, que se destinam a concretizar este raciocínio, com destaque para ao Pacto Global ou Pacto de Integridade de iniciativa promovida pela Organização das Nações Unidas (ONU).

A proposta fora anunciada no Fórum Econômico Mundial (Fórum de Davos), em 31 de janeiro de 1999, pelo ex-secretário geral da Organização das Nações Unidas (ONU), Kofi Annan, que objetivou encorajar as empresas a adotarem comportamentos de responsabilidade social corporativa e sustentabilidade.

Esta iniciativa contou com o apoio de cinco agências das Nações Unidas, sendo elas, o Escritório do Alto Comissariado dos Direitos Humanos (OHCHR), a Organização Internacional do Trabalho (OIT), o Programa das Nações Unidas para o Meio Ambiente (PNUMA) e a (UNIDO), lideradas pelo programa das Nações Unidas para o Desenvolvimento (PNUD) (PACTO GLOBAL, 2013).

O Pacto Global é um instrumento de livre ajuntamento pelas empresas, instituições da sociedade civil e demais interessados, possuindo atualmente mais de 5.200 organizações signatárias, articuladas por 150 redes pelo mundo afora.

Já o papel do Pacto de Integridade é como uma ferramenta para busca de limpeza das contratações dos interesses públicos, inclui uma análise abrangente do ambiente que têm sido implementadas os pactos de integridade na Colômbia e quebra a análise de um grupo de condições para as quais foram classificadas em:

a) pontos fortes;

b) oportunidades; e

c) os pontos fracos.

O documento começa por identificar um elemento importante na implementação de pactos de integridade, mencionando que o ambiente na Colômbia é fortemente influenciado pela necessidade que as diferentes instituições do Estado colombiano para mostrar tanto as posições como ações concretas contra a corrupção.

Por fim, Dirani (2000), afirma que qualquer motivação de um Estado para combater a corrupção, pode-se dizer que, pelo alto grau de politização que sempre 
envolve os contratos públicos, como um dos mais utilizados para pagar setores e favores políticos de contribuições de campanha, sem ter o apoio do Estado é quase impossível ter um impacto sobre a corrupção nesses contratos públicos.

\section{Metodologia}

No desenvolvimento de um estudo, independentemente da modalidade, tornase imperativo o emprego de procedimentos metodológicos para a sua descrição e explicação, bem como para o alcance dos resultados desejados e validade dos mesmos, de modo que diferentes necessidades e situações são preenchidas com diferentes métodos de pesquisa, que inclusive podem ser conjugados (YIN, 2010).

Nesse sentido, cada pesquisa possui especificidades, de modo que a previsão e provisão de recursos se darão de acordo com estas. Deste ponto decorre a necessidade de classificar as pesquisas, haja vista a necessidade de viabilizar elementos para a solução da problemática proposta, bem como conferir maior racionalização das etapas da pesquisa.

Não há uma classificação imperativa da pesquisa, mas diferentes modos de classificação. No presente trabalho se optou por seguir Gil (2010), o qual propõe que as pesquisas sejam classificadas quanto à finalidade, objetivos e métodos empregados.

No que concerne aos objetivos é exploratória e descritiva. Esta, ao passo em que serão expostas características das Instituições Públicas para análise e construção de uma proposta de um Sistema de Integridade, bem como a descrição dos passos realizados para tanto. Aquela em função dessas pesquisas permitirem maior familiaridade com o problema, tornando-o mais explícito, voltando-se para a análise dos mais variados aspectos sobre o fato ou fenômeno estudado (GIL, 2010), permitindo ao pesquisador aumentar sua experiência em torno de determinado problema (TRIVIÑOS, 1987).

Quanto à abordagem da pesquisa, se classifica como qualitativa, por se ater a compreensão e interpretação do fenômeno corrupção, entendendo o contexto e dinâmica das instituições públicas. Logo, a pesquisa está orientada qualitativamente pela estruturação do seu objeto de estudo proposto para o caso em tela.

Quanto aos procedimentos, é bibliográfico por desenvolver uma investigação de conhecimentos sistematizados em livros, artigos, dissertações, monografias e 
teses analisando a temática de acordo com as contribuições teóricas buscadas (GONSALVES, 2007), bem como por envolver informações disponíveis em sites especializados em fornecimento de informações pertinentes ao estudo.

\section{Resultados e Discussão}

Ao adotar uma definição mínima para o termo corrupção, é pertinente discutir (e demonstrar aos casos em análise) alguns diferentes tipos ou modos de corrupção.

A princípio vamos considerar os três tipos propostos por Gambetta (2004).

Para Gambetta (2004), a corrupção pressupõe em um jogo que envolve três atores: o representante, o corruptor e o representado (fiduciary, corruptor and truster).

Existem três tipos de jogos comumente usados. No primeiro momento, há uma ruptura clara das regras pelo representante, de modo que favoreça o corruptor, em troca de um suposto suborno.

Um exemplo claro seria um indivíduo (corruptor) pagar um agente da Polícia Federal (representante) para alcançar um passaporte diplomático - ou seja, um serviço que ele não deveria fazer. Isso fere os demais cidadãos que nesse caso são os (representados) que não pagaram o suborno e têm apenas um passaporte comum (PRAÇA, 2011).

No tocante ao exemplo explícito acima, há uma percepção difundida no Brasil de que os servidores (colaboradores) públicos que são identificados ou pegos em práticas corruptas não são passíveis de punição. Entretanto, até o momento, não havia evidência que desse sustentação a essa afirmação.

Inicialmente, as leituras permitiram afirmar que o tema corrupção, é um dos mais mencionados de forma descritiva, pois, pressupõe que existe um considerável número de pesquisa empírica sobre o assunto e, pode-se inferir que o tema é um conceito teórico e subjetivo tornando difícil de conduzir o pensamento estratégico sobre as suas causas para poder minimizar os seus efeitos.

Definitivamente, por meio das revisões bibliográficas estudadas ainda não foi encontrado no Brasil um plano de ação sistemático e eficaz de combate à corrupção, acarretando relativamente à percepção de se estar perdendo essa guerra crucial.

A esse sentimento coletivo da sociedade brasileira somam-se os números da Transparência Internacional, cujo ranking da corrupção em 2012 ocupava o lugar 69음 do ranking; e em 2019 o Índice de Percepção da Corrupção (IPC) de 2019 passou 
para o 106임a, e a TI garantiu que o Brasil obteve uma péssima nota pelo segundo ano consecutivo.

A evidência da ineficiência e ineficácia do controle da corrupção no Brasil é clara, e tem várias causas, passando por aspectos históricos, culturais e sociológicos, mas, sobretudo com profundas raízes na maneira como foi concebido o sistema de controle no país, reflexo de um desordenamento do crescimento de determinadas instituições centrais nesse combate, ainda hoje muito longe do modelo ideal.

Como concepção teórica da pesquisa, a luta contra a corrupção no Brasil deveria ser travada destacadamente em dois campos preparados para esse dever:

i) de um lado, o Poder Judiciário, com desempenho premente nesse âmbito dos distintos ramos do Ministério Público brasileiro e;

ii) do outro, o Sistema de Controle Externo, cuja função de análise cotidiana dos gastos públicos necessitaria ser partilhado entre três instituições: Poder Legislativo, Tribunal de Contas da União (TCU) e Ministério Público de Contas.

Os corruptos no Brasil deveriam ser condenados à miséria, e o crime contra o patrimônio público deveria ser considerado como um crime hediondo, inafiançável, pois sua natureza se dá por antecipação, ou seja, a premeditação é concebida, arquitetada e formulada com requinte de crueldade causando danos irreparáveis à sociedade, pois a corrupção não é um crime violento, mas deveria existir uma pena de empobrecimento, deixar o corrupto pobre no sentido da lei.

Nos dias atuais, o corrupto é preso e continua rico, pois a corrupção não provoca temor, além de gerar indignação na sociedade, mas infelizmente a sociedade não tem medo do corrupto. Esses crimes contra a administração pública deveriam ser tratados como crimes hediondos, ou seja, passíveis de punições mais rigorosas possíveis.

A falta de punição para os casos de corrupção e desvio de dinheiro público servem de estímulo para novas fraudes ao erário, retirando recursos de áreas essenciais, como saúde e educação. Assim dessa forma, alguns indivíduos argumentam que essas afirmações eram a conclusão de uma percepção equivocada derivada do crescimento recente de medidas de anticorrupção.

Por fim, uma das razões mais óbvias para a falta de evidência da citada impunibilidade, emana da dificuldade de identificarem casos concretos de corrupção 
para, então, mensurar se tais casos são ou não punidos pelo Poder Judiciário (ALENCAR; GICO JR, 2011).

\section{Conclusão}

O presente estudo, não teve o condão pretensioso de proporcionar uma conclusão no sentido de dar um ponto final no processo de pesquisa em relação ao assunto "corrupção", haja vista a riqueza de dados e fatos e a amplitude do tema e o desdobramento do assunto, pois ainda acredita-se que serão estudadas e novas propostas serão apresentadas.

Portanto, não cabe finalizá-lo, pelo contrário, remete-se ao entendimento de algumas considerações entendidas ao longo da investigação e que devem ser ponto de partida para outras pesquisas vinculadas ao objeto de estudo em questão.

O embrião desta pesquisa iniciou-se a partir da proposta de realizar um sistema de integridade aos órgãos governamentais no Brasil no tocante a corrupção.

Desta forma, o objetivo desse artigo foi de realizar uma análise sobre a relação entre a corrupção e os organismos governamentais do Brasil, e sugerir um Sistema de Integridade aos órgãos governamentais como um instrumento para combater a Corrupção.

Ao resgatar o objetivo proposto foi possível identificar que ele foi alcançado quando se identificou que combater a corrupção e contê-la em patamares civilizados, infelizmente, não é um dos pontos de destaque a nível nacional (Brasil).

O Brasil não é o país da impunidade. Mas aqui quase não se pune com regime fechado os crimes mais graves. Se não mudar esse perfil, os Sistemas Judiciário vão trabalhar para fazer o controle social do pobre. Assim, o Brasil é e continuará sendo um país corrupto simplesmente porque está estruturado para sê-lo!

Aprofundado na sociedade brasileira, a corrupção é hoje um câncer que se difunde praticamente por todas as esferas de poder, em especial as instituições públicas como já foram citadas no corpo desse artigo.

Como proposta para um Sistema de Integridade aos órgãos governamentais, sugere-se: 
a) Que o Congresso Nacional delibere reformas estruturantes de anticorrupção agasalhada no pacote de medidas elaboradas por especialistas da área;

b) Que o Poder Judiciário e o Ministério Público ajam de frente com mais eficiência administrativa;

c) Que o governo federal afaste qualquer membro investigado por corrupção, além de propor ao Congresso Nacional medidas de anticorrupção e devendo abster-se de hostilizar os profissionais da imprensa;

d) Que a sociedade brasileira exerça conscientemente seus direitos de voto em todas as eleições, elegendo candidatos com passado limpo, que tenham compromisso com a pauta anticorrupção e respeito aos valores democráticos.

Nesse contexto, é premente que o Brasil continua engatinhando no campo da educação. Ainda não foi dado conta que a educação é a ênfase que se deveria dar em termos de soluções e recursos. Acabam preferindo partir para o assistencialismo, em vez de se viabilizar o desenvolvimento dos jovens para que, realmente, entre no mercado de trabalho, arremetendo no próprio desenvolvimento para se ter um número maior de empregos.

Percebe-se uma incidência da lei. Mas o Judiciário eleitoral deveria atuar mais de ofício. O desempenho é vinculado e depende da provocação de um antagonista, de um partido opositor, de um candidato opositor ou então do Ministério Público ou um fiscal da lei.

No Brasil não precisa de novas leis, o que se precisa é de homens que respeitem as leis existentes e, especialmente, de homens públicos. E não respeitando, o cidadão necessita estar atento e não conferir a ele um novo mandato, se é que alcançou um anteriormente.

A aplicação dessas propostas foi observada para os fins estabelecidos desse estudo e para fortalecer o desenvolvimento, por cada um dos Estados Partes, das estruturas necessárias para prevenir, detectar, punir, erradicar a corrupção, promover, facilitar e regular a cooperação entre os Estados da Unidade Federativa do País (UF).

Os atos de corrupção designadamente vinculados ao seu exercício, os Estados acordam em considerar a aplicabilidade de medidas, em seus sistemas institucionais, designados a criar, manter e fortalecer os mecanismos para incitar a participação da 
sociedade civil e de organizações não governamentais nos esforços para prevenir a corrupção.

Concluiu-se que cada Estado da UF do Brasil, em conformidade com os princípios fundamentais de seu ordenamento jurídico, deveria adotar medidas apropriadas para promover a transparência e a obrigação de prestar contas na gestão de recursos públicos.

Essas medidas incluem um sistema de normas de contabilidade e auditoria, assim como a supervisão correspondente e sistemas eficazes e eficientes de gestão de riscos e controle interno.

Por fim, esse estudo não se esgota por si só e novos estudos devam dar continuidade para revelar novos resultados. Essa pesquisa teve um desdobramento e motivação de outros estudos já publicados pela Revista Multidisciplinar do Nordeste Mineiro de autoria do mesmo autor deste estudo, os quais cita-se:

i) Dificuldades da Inclusão de Pessoas com Deficiência no Mercado de Trabalho;

ii) Liderança: seu papel visando o clima e a cultura nas organizações;

iii) Desmotivação no ambiente de trabalho: fatores que geram medidas para a reversão;

iv) Inclusão de pessoas com deficiência no mercado de trabalho: a relevância das atividades mercadológicas e sociais;

v) O planejamento estratégico e o seu papel para a sobrevivência das micro e pequenas empresas;

vi) A cultura organizacional e sua relação com o desempenho das empresas e;

vii) Um estudo sobre o controle do estoque hospitalar com ênfase no gerenciamento sobre os custos e a armazenagem.

\section{Referências}

ALENCAR, C. H. R. GICO JR., I. Corrupção e judiciário: a (in)eficácia do sistema judicial no combate à corrupção. Rev. direito GV [online]. 2011, vol.7, n.1, pp. 7598. ISSN 1808-2432. 2011. 
DIRANI, Valeria Merino y LOZANO, Juan. (org.): La hora de la transparencia en América Latina, transparencia internacional para América Latina y el Caribe.TILAC, Berlin, dezembro, 1996.

Banco interamericano de desarrollo conferencia sobre transparencia y desarrollo en américa latina y el caribe: comentarios a "los pactos de integridad:Logros, limitantes y perspectiva. Mayo 2000.

GAMBETTA, D. "Corruption: an analytical map", In: Kreike, E. \& Jordan, W. C. (eds.) Corrupt Histories. New York: University of Rochester Press, 2004.

GIL, Antonio Carlos. Como elaborar projetos de pesquisa. 5.ed. São Paulo: Atlas, 2010.

GONSALVES, Elisa Pereira. Iniciação à pesquisa cientifica. 4.ed. Campinas: Editora Alínea, 2007.

JOHNSTON, Michael, - Syndromes of corruption - Wealth, Power and Democracy. Cambridge: University Press. 2005. (tradução pelo autor)

KLITGAARD, Robert. A Corrupção sob controle. Rio de Janeiro: Jorge Zahar Editor, 1994, p. 85.

. Controlling corruption. Berkeley: University of California Press.1988

KURY, Mário da Gama. Aristóteles: Política. Tradução, introdução e notas. Ed. Universidade de Brasília, 1985.

NTALAJA-NZONGOLA, Georges. Corruption in transitional countries. Talking points for a Thematic Meeting at the $7^{\text {th }}$.DirectorUNDP Oslo Governance Centre International Student Festival Trondheim, Norway, 14 March 2003. 
PACTO GLOBAL. Pacto global. Rede Brasil. 2013. Disponível em <https://pactoglobal.org.br/noticia/122>. Acesso em 15 out 2020.

PEREIRA, José Matias. Reforma do estado e transparência: estratégias de controle da corrupção no Brasil. VII Congreso Internacional del CLAD sobre la Reforma del Estado y de la Administración Pública, Lisboa, Portugal, 8-11 oct. 2002.

PRAÇA, S., Corrupção e reforma institucional no Brasil, 1988-2008. Escola de economia, fundação Getúlio Vargas opinião pública vol.17 n.1 Campinas jun. 2011.

SANTOS, Wanderley Guilherme dos. Paradigma e história: a ordem burguesa na imaginação social brasileira, in Ordem burguesa e liberalismo político. São Paulo: Duas Cidades, 1978.

SILVA, M. F. G. A economia política da corrupção, Transparência Brasil, São Paulo, 2001.

SPECK, Bruno Wilhelm. Caminhos da Transparência. Source Book da Transparency International.Editora da Universidade Estadual de Campinas (SP) 2002.

SUÁREZ, F. M.; GORROCHATEGUI, N. "Corrupción organizacional: aspectos vinculados a la estructura de oportunidades en diversos tipos de organizaciones y casos de corrupción institucionalizados". Instituto de Investigaciones Administrativas - Facultad de Ciencias Económicas - Universidad de Buenos Aires. Santo Domingo 24 al 27 de octubre de 2000.

SUÁREZ, F. M.; CHRISTENSEN, A. La corrupción: aspectos culturales de la invisibilidad. Cumbre Anti-corrupción 2000. 21-23 de Septiembre, Arlington Virginia, 2000.

TRANSPARENCY INTERNATIONAL: National integrity systems. The TI source book, Berlin, 1996. 
TRANSPARÊNCIA INTERNACIONAL (2012). Disponível em $<$ http://www.portugues.rfi.fr/mundo/20121205-brasil-melhor-no-ranking-de-corrupcaoda-transparencia-internacional> Acesso em: 19 jun. 2020.

TRANSPARÊNCIA INTERNACIONAL BRASIL, 2019. Disponível em < https://transparenciainternacional.org.br/ipc/>. Acesso em: 19 jun. 2020.

TRIVIÑOS, Augusto Nibaldo Silva. Introdução à pesquisa em Ciências Sociais: a pesquisa qualitativa na educação. São Paulo: Atlas, 1987. Disponível em: <http://pt.scribd.com/doc/84 708933/Livro-Introducao-a-pesquisa-em-CienciasSociais-Trivinos>. Acesso em: 27 abr. 2014.

YIN, Robert K. Estudo de caso: planejamento e métodos. 4.ed. Porto Alegre: Bookman, 2010. 